\title{
KARAKTERISTIK MIKROSTRUKTUR DAN FASA PADUAN Zr- 0,3\%Nb-0,5\%Fe-0,5\%Cr PASCA PERLAKUAN PANAS DAN PENGEROLAN DINGIN
}

\author{
Sungkono, Masrukan \\ Pusat Teknologi Bahan Bakar Nuklir - BATAN \\ Kawasan Puspiptek, Serpong, Tangerang Selatan, 15314 \\ e-mail: sungkhana@gmail.com \\ (Naskah diterima : 21-04-2015, Naskah direvisi: 06-05-2015, Naskah disetujui: 11-05-2015)
}

\begin{abstract}
ABSTRAK
KARAKTERISTIK MIKROSTRUKTUR DAN FASA PADUAN Zr-0,3\%Nb-0,5\%Fe-0,5\%Cr PASCA PERLAKUAN PANAS DAN PENGEROLAN DINGIN. Logam paduan Zr-Nb-Fe-Cr dikembangkan sebagai material kelongsong elemen bakar dengan fraksi bakar tinggi untuk reaktor daya maju. Dalam penelitian ini telah dibuat paduan $\mathrm{Zr}-0,3 \% \mathrm{Nb}-0,5 \% \mathrm{Fe}-0,5 \% \mathrm{Cr}$ yang mendapat perlakuan panas pada temperatur 650 dan $750^{\circ} \mathrm{C}$ dengan waktu penahanan 1-2 jam. Tujuan penelitian adalah mendapatkan karakter paduan $\mathrm{Zr}-0,3 \% \mathrm{Nb}-0,5 \% \mathrm{Fe}-0,5 \% \mathrm{Cr}$ pasca perlakuan panas dan pengerolan dingin yaitu mikrostruktur, struktur kristal dan fasa-fasa yang ada dalam paduan. Hasil penelitian menunjukkan bahwa paduan $\mathrm{Zr}-0,3 \% \mathrm{Nb}-0,5 \% \mathrm{Fe}-0,5 \% \mathrm{Cr}$ pasca perlakuan panas $\left(650^{\circ} \mathrm{C}, 1-2\right.$ jam) mempunyai struktur butir ekuiaksial dengan ukuran butir bertambah besar seiring dengan bertambahnya waktu penahanan. Sementara itu, pasca perlakuan panas $\left(750^{\circ} \mathrm{C}, 1-2 \mathrm{jam}\right)$ terjadi perubahan mikrostruktur paduan dari butir ekuiaksial dan kolumnar menjadi butir ekuiaksial lebih besar. Paduan $\mathrm{Zr}-0,3 \% \mathrm{Nb}-0,5 \% \mathrm{Fe}-0,5 \% \mathrm{Cr}$ pasca perlakuan panas $\left(650^{\circ} \mathrm{C}, 1 \mathrm{jam}\right)$ dan $\left(750^{\circ} \mathrm{C}, 1 \mathrm{jam}\right)$ tidak dapat dirol dingin dengan reduksi tebal $5-10 \%$, sedangkan pasca perlakuan panas $\left(650^{\circ} \mathrm{C}, 2 \mathrm{jam}\right)$ dan $\left(750^{\circ} \mathrm{C}, 1.5-2 \mathrm{jam}\right)$ mampu menerima deformasi dingin dengan reduksi ketebalan 5-10\% tanpa mengalami keretakan. Senyawa $\mathrm{Zr}_{2} \mathrm{Fe}, \mathrm{ZrCr}_{2}$ dan $\mathrm{FeCr}$ teridentifikai dari hasil uji kristalografi paduan $\mathrm{Zr}-0,3 \% \mathrm{Nb}-0,5 \% \mathrm{Fe}-0,5 \% \mathrm{Cr}$.
\end{abstract}

Kata kunci: paduan $\mathrm{Zr}-0,3 \% \mathrm{Nb}-0,5 \% \mathrm{Fe}-0,5 \% \mathrm{Cr}$, perlakuan panas, pengerolan dingin, mikrostruktur, kristalografi.

\section{ABSTRACT}

MICROSTRUCTURE AND PHASE CHARACTERISTICSOF Zr-0.3\%Nb-0.5\%Fe-0.5\%Cr ALLOY POST HEAT TREATMENT AND COLD ROLLING. Zr-Nb-Fe-Cr alloys was developed as fuel elements cladding with high burn up for advanced power reactors. In this research has been made of $\mathrm{Zr}-0.3 \% \mathrm{Nb}-0.5 \% \mathrm{Fe}-0.5 \% \mathrm{Cr}$ alloy were heat treated with varying temperatures at 650 and $750^{\circ} \mathrm{C}$ for 1 until 2 hours. The objectives of this research was to obtain the character of $\mathrm{Zr}-0.3 \% \mathrm{Nb}-0.5 \%$ $\mathrm{Fe}-0.5 \% \mathrm{Cr}$ alloy post heat treatment and cold rolling, microstructure nomenclature, crystal structure and phases that presents in the alloy. The results of this experiment showed that the microstructures of $\mathrm{Zr}-0.3 \% \mathrm{Nb}-0.5 \% \mathrm{Fe}-0.5 \% \mathrm{Cr}$ alloy post heat treatment (650ㅇ․ $1-2$ hours) had equiaxial grain structure with an enlarged size with increasing of the retention time. Meanwhile, post heat treatment $\left(750^{\circ} \mathrm{C}, 1-2\right.$ hours) occurred the microstructures evolution of alloy from equiaxial and columnar became equiaxial and columnar relatively large, and subsequently became the larger equiaxial grains. $\mathrm{Zr}-0.3 \% \mathrm{Nb}-0.5 \% \mathrm{Fe}-0.5 \% \mathrm{Cr}$ alloy post heat treatment $\left(650^{\circ} \mathrm{C}, 2 \mathrm{~h}\right)$ and $\left(750^{\circ} \mathrm{C}\right.$, 1.5-2 hours) can undergo cold deformation without cracking when thickness reduction between 5 
to $10 \%$. The phases formation of $\mathrm{Zr}_{2} \mathrm{Fe}, \mathrm{ZrCr}_{2}$ and $\mathrm{FeCr}$ compounds can improve the mechanical strength and the corrosion resistance of $\mathrm{Zr}-0.3 \% \mathrm{Nb}-0.5 \% \mathrm{Fe}-0.5 \% \mathrm{Cr}$ alloy.

Keywords: $\mathrm{Zr}-0.3 \% \mathrm{Nb}-0.5 \% \mathrm{Fe}-0.5 \% \mathrm{Cr}$ alloy, heat treatment, cold rolling, microstructure, phase.

\section{PENDAHULUAN}

Salah satu tantangan utama energi nuklir adalah daya saing (kompetitiveness) terhadap sumber energi lainnya. Agar lebih kompetitif industri nuklir harus meminimalkan biaya perawatan dan siklus bahan bakar tetapi tetap meningkatkan fitur keselamatan. Salah satu metode yang diterapkan untuk mencapai tujuan tersebut adalah menaikkan fraksi bakar dari bahan bakar nuklir. Dalam kondisi operasi normal dan terantisipasi di reaktor daya, kenaikan fraksi bakar bahan bakar nuklir akan menyebabkan kenaikan temperatur, waktu tinggal, perubahan dimensi, pembentukan hidrida dan tekanan internal elemen bakar nuklir. Kondisi ini dapat meningkatkan laju korosi, menurunkan ketangguhan material kelongsongnya. interaksi pelet-kelongsong (pellet-cladding interactions) dan interaksi mekanik pelet dan kelongsong (pellet-cladding mechanical interactions) sehingga berpotensi terjadinya kegagalan elemen bakar nuklir ${ }^{[1]}$. Hal ini dapat dihindari apabila kelongsong menggunakan material yang mempunyai ketahanan korosi tinggi, kekuatan mekanik tinggi, stabilitas iradiasi cukup tinggi dan tampang lintang serapan neutron termalnya rendah.

Logam paduan zirkonium sampai saat ini sukses digunakan sebagai material kelongsong bahan bakar reaktor daya dengan pendingin air. Logam paduan zirkonium harus ditingkatkan kinerjanya apabila digunakan dalam kondisi fraksi bakar bahan bakar tinggi. Untuk memenuhi tujuan tersebut maka dikembangkan paduan berbasis zirkonium dengan niobium (Nb) sebagai unsur pemadu utama. Hal ini dilakukan guna meningkatkan kekuatan mekanik dan ketahanan korosi paduan zirkonium dalam air dan uap air lewat jenuh.
Selain niobium juga ditambahkan besi (Fe) dan khrom (Cr) untuk menstabilkan ketahanan korosi dalam air pada temperatur tinggi dan meningkatkan kekuatan mekanik paduan zirkonium. Adanya unsur $\mathrm{Nb}, \mathrm{Fe}$ dan $\mathrm{Cr}$ dalam ingot paduan zirkonium tidak mempengaruhi ekonomi neutron termal bahan bakar nuklir karena tampang lintang serapan neutron termalnya sangat rendah

Wang et al. telah meneliti perilaku korosi beberapa paduan $\mathrm{Zr}-\mathrm{Fe}-\mathrm{Cr}$ yang mengandung $\mathrm{Fe}(0,2-1 \%)$ dan $\mathrm{Cr}(0,1-0,6 \%)$ dalam lingkungan uap pada $500^{\circ} \mathrm{C}$ dan mendapatkan bahwa paduan $\mathrm{Zr}-0,1 \% \mathrm{Fe}$ $0,6 \% \mathrm{Cr}$ mempunyai ketahanan korosi tinggi karena adanya presipitat $\mathrm{Zr}(\mathrm{Fe}, \mathrm{Cr})_{2}$ dalam matriks relatif banyak dibandingkan paduan $\mathrm{Zr}-\mathrm{Fe}-\mathrm{Cr}$ lainnya ${ }^{[2]}$. Lim et al. mendapatkan fakta bahwa temperatur rekristalisasi paduan $\mathrm{Zr}-\mathrm{xNb}$ naik seiring dengan meningkatnya kandungan $\mathrm{Nb}$. Struktur rekristalisasi seragam dengan nilai kekerasan rendah diperoleh apabila paduan $\mathrm{Zr}$ yang mengandung $0,4 \%$ atau lebih $\mathrm{Nb}$ dianil pada temperatur $600-700^{\circ} \mathrm{C}^{[3]}$. Kim et al. mendapatkan fakta ketahanan korosi paduan $\mathrm{Zr}-\mathrm{Nb}$ yang baik dalam lingkungan air pada $360^{\circ} \mathrm{C}$ diperoleh pada kandungan $0,2-0,3 \%$ berat $\mathrm{Nb}$ dan temperatur anil $570^{\circ} \mathrm{C}$. Ketahanan korosi paduan $\mathrm{Zr}-\mathrm{Nb}$ dikendalikan oleh kelarutan $\mathrm{Nb}$ dalam fasa $\alpha-Z r$ dan $\beta-Z r$ yang ditentukan oleh temperatur ani[[4].

Zhinan. et al. telah mengadakan penelitian terhadap perilaku paduan Zr705 pasca pengerolan panas dan pengerolan dingin dalam rentang temperatur $200 \sim 850^{\circ} \mathrm{C}$. Zhinan mendapakan bahwa pada temperatur kurang dari $500^{\circ} \mathrm{C}$, kekerasan spesimen paduan Zr705 pasca pengerolan panas lebih rendah dibandingkan kekerasan spesimen pasca pengerolan dingin. Transformasi fasa $\beta$ ke fase $\omega$ dalam mikrostruktur paduan Zr705 pasca pengerolan panas lebih rendah 
dibandingkan spesimen pengerolan dingin. Proses rekristalisasi sempurna paduan Zr705 terjadi pada $700^{\circ} \mathrm{C}^{[5]}$. Oh et al. mendapatkan bahwa selama perlakuan panas fraksi butir terekristalisasi pada paduan Zr-Nb berkurang dengan meningkatnya kadar $\mathrm{Nb}$. Paduan $\mathrm{Zr}$ - $\mathrm{Nb}$ pasca pengerolan dingin memiliki hidrida yang terpresipitasi di dalam butir sepanjang arah pengerolan. Presipitat $\beta-\mathrm{Nb}$ yang memiliki kelarutan tinggi hidrogen, menghambat terhadap pengendapan hidrida, sehingga meningkatkan ketahanan paduan Zr-Nb terhadap penggetasan hidrida[ ${ }^{[6]}$.

Berdasarkan uraian tersebut di atas diketahui bahwa mikrostruktur dan fasa-fasa yang ada mempengaruhi perilaku korosi dan mekanik paduan $\mathrm{Zr}-\mathrm{Nb}$. Untuk maksud tersebut maka pada penelitian ini akan dilakukan pengamatan mikrostrukturdan fasa-fasa yang ada dalam ingot paduan $\mathrm{Zr}$ - Nb- Fe- $\mathrm{Cr}$ pasca perlakuan panas dan pengerolan dingin. Proses perlakuan panas dan pengerolan dingin merupakan salah satu tahapan dalam proses fabrikasi bahan struktur elemen bakar nuklir. Proses perlakuan panas tersebut dilakukan untuk mendapatkan mikrostruktur ingot paduan $\mathrm{Zr}$ - Nb- Fe-Cr yang bersifat lunak sehingga memudahkan proses pengerjaan paduan berikutnya. Pengerolan dingin dimaksudkan untuk mendapatkan mikrostruktur paduan $\mathrm{Zr}-\mathrm{Nb}-\mathrm{Fe}-\mathrm{Cr}$ yang lebih kuat dan penyelesaian permukaan lebih baik.

Penelitian ini mempunyai tujuan untuk mendapatkan karakter ingot paduan Zr- 0,3\% Nb-0,5\%Fe-0,5\%Cr setelah proses perlakuan panas dan pengerolan dingin yaitu mikrostruktur, struktur kristal dan fasa-fasa yang ada dalam paduan. Hipotesa yang diajukan adalah perlakuan panas dan deformasi dingin diduga dapat mengubah bentuk mikrostruktur dari butir ekuiaksial ke bentuk pipih terdeformasi sehingga dapat meningkatkan kekuatan mekanik paduan $\mathrm{Zr}$ - Nb-Fe-Cr.

\section{METODOLOGI}

Bahan baku yang digunakan dalam pembuatan ingot paduan $\mathrm{Zr}-\mathrm{Nb}-\mathrm{Fe}-\mathrm{Cr}$ adalah sponge zirkonium, serbuk niobium, serbuk besi dan serbuk khrom. Bahan lain yang digunakan adalah resin acryfic dan pengeras, kertas ampelas, kain poles, pasta intan, larutan etsa, dan alkoholuntuk preparasi metalografi sampel paduan $\mathrm{Zr}-\mathrm{Nb}-\mathrm{Fe}-\mathrm{Cr}$.

Peralatan yang digunakan untuk pembuatan ingot paduan $\mathrm{Zr}-\mathrm{Nb}-\mathrm{Fe}-\mathrm{Cr}$ adalah nesin pres dan tungku peleburan. Peralatan lain yang digunakan adalah tungku pemanas untuk perlakuan panas, mesin potong, mesin gerinda dan polesuntuk preparasi metalografi, mesin rol untuk mereduksi ketebalan sampel paduan $\mathrm{Zr}-\mathrm{Nb}-\mathrm{Fe}-\mathrm{Cr}$. Selain itu, mikroskop optik digunakan untuk pengamatan mikrostruktur dan difraktometer sinar-X untuk uji kristalografi paduan $\mathrm{Zr}-\mathrm{Nb}$ Fe-Cr.

Sejumlah ingot paduan $\mathrm{Zr}-0,3 \% \mathrm{Nb}-0,5 \% \mathrm{Fe}-0,5 \% \mathrm{Cr}$ dibuat dengan cara melebur kompakan sponge $\mathrm{Zr}$, serbuk $\mathrm{Nb}$, $\mathrm{Fe}$ dan $\mathrm{Cr}$ dalam tungku peleburan vakum. Ingot $\mathrm{Zr}-0,3 \% \mathrm{Nb}-0,5 \% \mathrm{Fe}-0,5 \% \mathrm{Cr}$ mengalami remelting sebanyak 5 kali dengan maksud agar paduan lebih homogen. Salah satu tahapan untuk meningkatkan ketangguhan paduan dapat dilakukan dengan cara perlakuan panas terhadap ingot paduan $\mathrm{Zr}-0,3 \% \mathrm{Nb}-0,5 \% \mathrm{Fe}-0,5 \% \mathrm{Cr}$. Proses perlakuan panas ini mempunyai tujuan untuk mendapatkan mikrostruktur berupa butir ekuiaksial yang seragam, sehingga paduan lebih lunak dan memudahkan proses pengerjaan paduan berikutnya.

Paduan $\quad \mathrm{Zr}-0,3 \% \mathrm{Nb}-0,5 \% \mathrm{Fe}-0,5 \% \mathrm{Cr}$ mendapat perlakuan panas pada temperatur $650^{\circ} \mathrm{C}$ dan $750^{\circ} \mathrm{C}$ dengan waktu penahanan masing-masing 1 ; 1,5; dan 2 jam, serta pendinginan lambat di dalam tungku. Proses perlakuan panas ingot dilakukan di dalam tungku pemanas dalam lingkungan gas Argon. Selanjutnya, sejumlah sampel $\mathrm{Zr}-\quad 0,3 \% \mathrm{Nb}-\quad 0,5 \% \mathrm{Fe}-\quad 0,5 \% \mathrm{Cr}$ pasca perlakuan panas dirol dingin pada temperatur 
kamar. Pengerolan sampel dilakukan secara bertahap hingga diperoleh reduksi ketebalan (r) yaitu 5 , dan $10 \%$.

Preparasi metalografi terhadap sampel ingot leburan, pasca perlakuan panas, serta pasca perlakuan panas dan pengerolan dingin dilakukan melalui 5 (lima) tahapan yaitu proses pemotongan untuk mendapatkan sampel metalografi, pembingkaian, penggerindaan, pemolesan, dan pengetsaan ${ }^{[7]}$. Penggerindaan sampel menggunakan mesin gerinda dengan kertas ampelas grit 320 sampai dengan 2.000 mesh. Sementara itu, pemolesan sampel menggunakan mesin poles dengan bahan poles yaitu pasta intan grit $0,1 \mu \mathrm{m}$. Selanjutnya sampel pasca poles dietsa dengan metoda usap. Larutan etsa yang digunakan adalah campuran $15 \mathrm{ml} \mathrm{HNO}_{3}, 30$ $\mathrm{mL} \mathrm{HF}, 30 \mathrm{~mL} \mathrm{HCl}$, dan $25 \mathrm{~mL}$ aquades.

Pengamatan mikrostruktur terhadap sampel paduan $\mathrm{Zr}-0,3 \% \mathrm{Nb}-0,5 \% \mathrm{Fe}-0,5 \% \mathrm{Cr}$ pasca pengetsaan dilakukan dengan menggunakan mikroskop optik. Sementara itu untuk mengetahui fasa-fasa yang ada dalam paduan $\mathrm{Zr}-0,3 \% \mathrm{Nb}-0,5 \% \mathrm{Fe}-0,5 \% \mathrm{Cr}$ pasca perlakuan panas dan pengerolan dingin digunakan peralatan $X$-ray difractometer (XRD)

\section{HASIL DAN PEMBAHASAN}

\section{a. Mikrostruktur}

Produk pertama dari proses peleburan kompakan campuran $\mathrm{Zr}, \mathrm{Nb}, \mathrm{Fe}$ dan $\mathrm{Cr}$ menggunakan tungku peleburan vakum adalah ingot paduan $\mathrm{Zr}$ - $0,3 \% \mathrm{Nb}-0,5 \% \mathrm{Fe}-0,5 \% \mathrm{Cr}$. Mikrostruktur ingot paduan $\mathrm{Zr}-0,3 \% \mathrm{Nb}-0,5 \% \mathrm{Fe}-0,5 \% \mathrm{Cr}$ mempunyai butir dengan bentuk dendrite dan acicular seperti yang ditunjukkan pada Gambar 1.

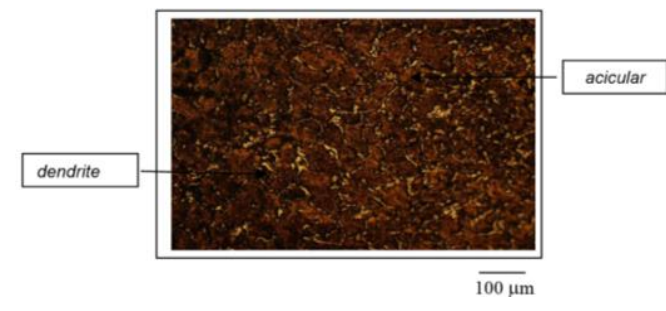

Gambar 1. Mikrograf ingot paduan $\mathrm{Zr}-0,3 \% \mathrm{Nb}-0,5 \% \mathrm{Fe}-0,5 \% \mathrm{Cr}$

Oleh karena mikrostruktur ingot paduan mempunyai 2 (dua) bentuk butir berbeda ditambah dengan adanya efek segregasi dan stacking fault yang terjadi selama proses presipitasi paduan, maka akanmeningkatkan konsentrasi dislokasi dan tegangan sisa dalam paduan.

Hal ini menyebabkan ingot paduan mempunyai sifat keras dan getas. Perilaku paduan demikian tidak diinginkan dalam proses fabrikasi karena benda kerja mudah patah sehingga menyulitkan dalam proses pengerjaannya. Untuk mengatasi hal tersebut, maka paduan mendapat perlakuan panas pada temperatur dan waktu yang sesuai agar paduan lebih lunak sehingga memudahkan pengerjannya. Dalam penelitian ini, ingot paduan Zr- $0,3 \% \mathrm{Nb}-0,5 \% \mathrm{Fe}-0,5 \% \mathrm{Cr}$ dipanaskan pada temperatur 650 dan $750^{\circ} \mathrm{C}$ dengan waktu penahanan masing-masing $1-2$ jam.

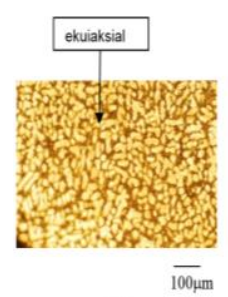

(a)

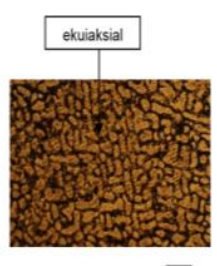

(b)

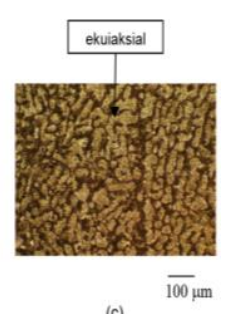

Gambar 2. Mikrograf ingot paduan $\mathrm{Zr}-\quad 0,3 \% \mathrm{Nb}-\quad 0,5 \% \mathrm{Fe}-0,5 \% \mathrm{Cr}$ pasca perlakuan panas pada temperatur $650^{\circ} \mathrm{C}$

(a) waktu penahanan 1 jam,

(b) waktu penahanan 1,5 jam;

(c) waktu penahanan 2 jam.

Gambar 2 memperlihatkan visual mikrostruktur yang diambil dengan mikroskop optik pada tiga perlakuan yang berbeda pada ingot paduan $\mathrm{Zr}-0,3 \% \mathrm{Nb}-0,5 \% \mathrm{Fe}-0,5 \% \mathrm{Cr}$ pasca perlakuan panas pada temperatur 
$650^{\circ} \mathrm{C}$ yang mana terlihat adanya perubahan struktur butir dari dendrite dan acicular (Gambar 1) menjadi butir ekuiaksial relatif kecil (Gambar 2a). Perubahan bentuk struktur butir tersebut memberikan dampak pada penurunan kekerasan paduan namun ukuran butir ekuiaksial yang kecil membuat paduan masih mempunyai kekerasan tinggi. Kondisi ini belum menguntungkan dalam proses pengerolan paduan karena dibutuhkan gaya pembentukan tinggi dan kemungkinan dapat retak pada deformasi besar. Untuk mengatasi masalah tersebut maka paduan $\mathrm{Zr}-0,3 \% \mathrm{Nb}-0,5 \% \mathrm{Fe}-0,5 \% \mathrm{Cr}$ harus mempunyai struktur butir ekuiaksial dengan ukuran relatif besar dan homogen supaya paduan mempunyai sifat lunak sehingga gaya pembentukannya rendah dan deformasi yang diterapkan relatif besar.

Selanjutnya, ingot paduan Zr- $\quad 0,3 \% \mathrm{Nb}-\quad 0,5 \% \mathrm{Fe}-0,5 \% \mathrm{Cr}$ dilakukan pemanasan pada temperatur tetap $\left(650^{\circ} \mathrm{C}\right)$ dengan waktu penahanan 1,5 jam (Gambar 2b) dan waktu penahanan 2 jam (Gambar 2c). Gambar 2b memperlihatkan gambar mikrostruktur paduan dengan struktur butir ekuiaksial dengan ukuran relatif lebih besar dibandingkan ukuran butir ekuiaksial dari Gambar 2a. Struktur butir ekuiaksial dari mikrostruktur (Gambar 2c) mempunyai ukuran lebih besar dibandingkan butir ekuiaksial pada Gambar 2a dan 2b.

Gambar mikrostruktur paduan Zr- $\quad 0,3 \% \mathrm{Nb}-\quad 0,5 \% \mathrm{Fe}-\quad 0,5 \% \mathrm{Cr}$ pasca perlakuan panas $650^{\circ} \mathrm{C}$ dengan waktu penahanan 1- 2 jam mempunyai bentuk butir yang sama yaitu ekuiaksial dengan ukuran butir bertambah besar seiring dengan bertambahnya waktu penahanan. Hal ini disebabkan karena ingot paduan Zr- $\quad 0,3 \% \mathrm{Nb}-\quad 0,5 \% \mathrm{Fe}-\quad 0,5 \% \mathrm{Cr}$ pada temperatur $650^{\circ} \mathrm{C}$ mempunyai gaya dorong rendah sehingga kemungkinan terjadinya proses pengintian dan pertumbuhan butir relatif setimbang. Kondisi tersebut memungkinkan atom-atom mampu menata diri dan butir ekuiaksial kecil bergabung satu sama lain dan membentuk butir baru ekuiaksial dengan ukuran lebih besar dan tidakseragam. Proses pertumbuhan butir ekuiaksial pada perlakuan panas pada $650^{\circ} \mathrm{C}$ dengan waktu penahanan $1-2$ jam belum sempurna. Untuk mengatasi permasalahan tersebut perlu penanganan pada ingot paduan $\mathrm{Zr}-0,3 \% \mathrm{Nb}-0,5 \% \mathrm{Fe}-0,5 \% \mathrm{Cr}$ dengan cara dipanaskan pada temperatur lebih tinggi yaitu $750^{\circ} \mathrm{C}$ dengan waktu penahanan sama. Hal ini disebabkan ingot paduan Zr- $\quad 0,3 \% \mathrm{Nb}-0,5 \% \mathrm{Fe}-0,5 \% \mathrm{Cr}$ pada temperatur $650^{\circ} \mathrm{C}$ mempunyai gaya dorong rendah sehingga kemungkinan terjadinya proses pengintian dan pertumbuhan butir relatif setimbang. Kondisi tersebut memungkinkan atom-atom mampu menata diri dan butir ekuiaksial kecil bergabung satu sama lain dan membentuk butir baru ekuiaksial dengan ukuran lebih besar dan tidakseragam. Proses pertumbuhan butir ekuiaksial pada perlakuan panas pada $650^{\circ} \mathrm{C}$ dengan waktu penahanan $1-2$ jam belum sempurna. Untuk mengatasi permasalahan tersebut perlu penanganan pada ingot paduan $\mathrm{Zr}-\quad 0,3 \% \mathrm{Nb}-\quad 0,5 \% \mathrm{Fe}-\quad 0,5 \% \mathrm{Cr}$ dengan cara dipanaskan pada temperatur lebih tinggi yaitu $750^{\circ} \mathrm{C}$ dengan waktu penahanan sama.

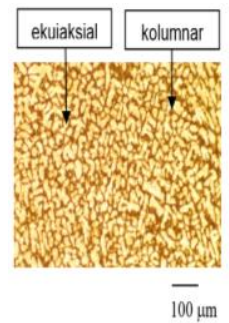

(a)

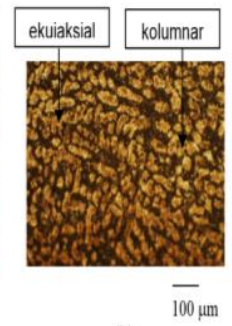

(b)

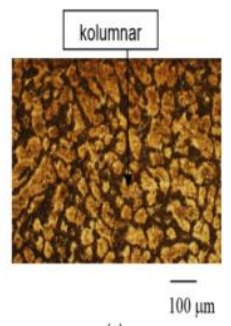

Gambar 3. Mikrograf ingot paduan $\mathrm{Zr}-\quad 0,3 \% \mathrm{Nb}-\quad 0,5 \% \mathrm{Fe}-0,5 \% \mathrm{Cr}$ pasca perlakuan panas pada temperatur $750^{\circ} \mathrm{C}$.
(a) waktu penahanan 1 jam,
(b) waktu penahanan 1,5 jam;
(c) waktu penahanan 2 jam.

Gambar 3 memperlihatkan mikrograf paduan $\mathrm{Zr}-0,3 \% \mathrm{Nb}-0,5 \% \mathrm{Fe}-0,5 \% \mathrm{Cr}$ pasca perlakuan panas pada temperatur $750^{\circ} \mathrm{C}$. Pada Gambar 3 terlihat mikrostruktur paduan $\mathrm{Zr}-0,3 \% \mathrm{Nb}-0,5 \% \mathrm{Fe}-0,5 \% \mathrm{Cr}$ denganstruktur 
butir campuran kolumnar dan ekuiaksial (Gambar 3a), butir kolumnar danekuiaksial mengalami pertumbuhan sehingga ukuran butirnya lebih besar (Gambar 3b), kemudian mengarah ke bentuk butir ekuiaksial dengan ukuran relatif besar (Gambar 3c). Kondisi ini menunjukkan bahwa perlakuan panas pada $750^{\circ} \mathrm{C}$ dengan waktu penahanan $1-2$ jam terjadi perubahan struktur butir baik bentuk maupun ukuran butir dalam mikrostruktur paduan $\mathrm{Zr}-0,3 \% \mathrm{Nb}-0,5 \% \mathrm{Fe}-0,5 \% \mathrm{Cr}$. Hal ini disebabkan gaya dorong pada temperatur $750^{\circ} \mathrm{C}$ lebih tinggi dibandingkan dengan $650^{\circ} \mathrm{C}$, sehingga kemungkinan terjadinya proses pengintian lebih rendah dibandingkan proses pertumbuhan butir ${ }^{[8]}$. Kondisi tersebut memberikan dampak pada penggabungan butir-butir ekuiaksial kecil menjadi butir kolumnar. Di lain pihak, butir-butir ekuiaksial kecil lainnya bergabung satu sama lain membentuk butir ekuiaksial baru dengan ukuran relatif besar. Dengan demikian mikrostruktur pada ingot paduan $\mathrm{Zr}$ - $\quad 0,3 \% \mathrm{Nb}-\quad 0,5 \% \mathrm{Fe}-\quad 0,5 \% \mathrm{Cr}$ pasca perlakuan panas $750^{\circ} \mathrm{C}$ mempunyai struktur campuran yaitu butir ekuiaksial dan kolumnar (Gambar 3a). Sementara itu, dengan bertambahnya waktu penahanan pada $750^{\circ} \mathrm{C}$ maka terjadi penggabungan butir kolumnar menjadi butir kolumnar lebih besar serta penggabungan butir ekuiaksial menjadi butir ekuiaksial dengan ukuran lebih besar (Gambar 3b). Selanjutnya dengan semakin lamanya waktu penahanan maka terjadi pertumbuhan dan penggabungan butir kolumnar dan ekuiaksial yang mengarah ke bentuk butir ekuiaksial baru dengan ukuran relatif besar (Gambar 3c) ${ }^{[7]}$. Ingot paduan $\mathrm{Zr}-\quad 0,3 \% \mathrm{Nb}-0,5 \% \mathrm{Fe}-0,5 \% \mathrm{Cr}$ pasca perlakuan panas $\left(750^{\circ} \mathrm{C}, 1-2\right.$ jam $)$ menjadi lebih lunak sehingga memungkinkan terjadinya proses deformasi cukup besar.

Paduan $\mathrm{Zr}-0,3 \% \mathrm{Nb}-0,5 \% \mathrm{Fe}-0,5 \% \mathrm{Cr}$

pasca perlakuan panas bersifat lunaksehingga perlu ditingkatkan kekuatan mekanik dan penyelesaian permukaannya menjadi lebih baik dengan carapengerolan dingin. Dalam penelitian ini, paduan $\mathrm{Zr}-\quad 0,3 \% \mathrm{Nb}-0,5 \% \mathrm{Fe}-0,5 \% \mathrm{Cr}$ pasca perlakuan panas dirol pada temperatur kamar dengan reduksi ketebalan 5 dan 10\%.

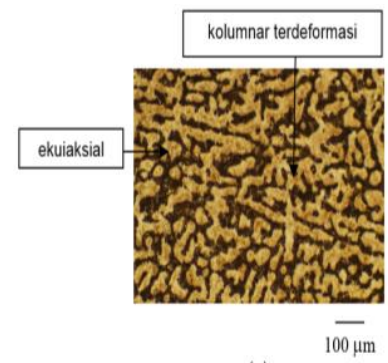

(a)

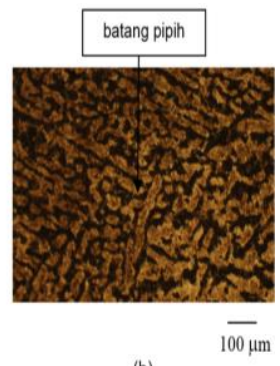

(b)
Gambar 4. Mikrograf ingot paduan Zr- $\quad 0,3 \% \mathrm{Nb}-\quad 0,5 \% \mathrm{Fe}-0,5 \% \mathrm{Cr}$ pasca perlakuan panas $\left(650^{\circ} \mathrm{C}, 1\right.$ jam) dan pengerolan dingin.

(a) $r=5 \%$; (b) $r=10 \%$

Gambar 4 memperlihatkan pengaruh deformasi akibat pengerolan dingin terhadap mikrostruktur dari ingot paduan Zr- $\quad 0,3 \% \mathrm{Nb}-\quad 0,5 \% \mathrm{Fe}-\quad 0,5 \% \mathrm{Cr}$ pasca perlakuan panas $\left(650^{\circ} \mathrm{C}, 1 \mathrm{jam}\right)$. Ingot paduan $\mathrm{Zr}-0,3 \% \mathrm{Nb}-0,5 \% \mathrm{Fe}-0,5 \% \mathrm{Cr}$ pasca perlakuan panas tersebut mempunyai mikrostruktur berupa butir ekuiaksial kecil sehingga mempunyai kekerasan tinggi dan bersifat getas. Pada proses pengerolan dingin, paduan mendapat tekanan yang besar dari dua buah rol kerja dengan reduksi tebal 5\%. Tekanan tersebut tidak mampu ditahan oleh gaya ikat antar atom paduan Zr- $\quad 0,3 \% \mathrm{Nb}-\quad 0,5 \% \mathrm{Fe}-\quad 0,5 \% \mathrm{Cr}$ pasca perlakuan panas $\left(650^{\circ} \mathrm{C}, 1 \mathrm{jam}\right)$ yangkeras dan getas, sehingga permukaan sampel retak $^{[0]}$. Sampel yang retak tersebut apabila dilihat mikrostrukturnya berupa campuran butir ekuiaksial dan kolumnar yang terdeformasi (Gambar 4a), untuk reduksi $10 \%$ mikrostrukturnya berupa batang pipih (Gambar 4b). Dengan demikian diketahui bahwa paduan $\mathrm{Zr}-0,3 \% \mathrm{Nb}-0,5 \% \mathrm{Fe}-0,5 \% \mathrm{Cr}$ pasca perlakuan panas $\left(650^{\circ} \mathrm{C}, 1 \mathrm{jam}\right)$ tidak memenuhi syarat untuk menerima perlakuan mekanik berupa pengerolan dingin dengan reduksi ketebalan $5-10 \%$. 


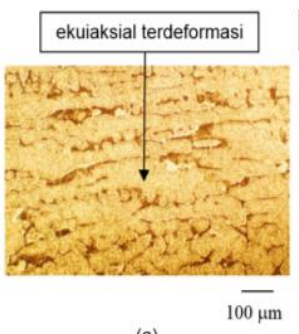

(a)

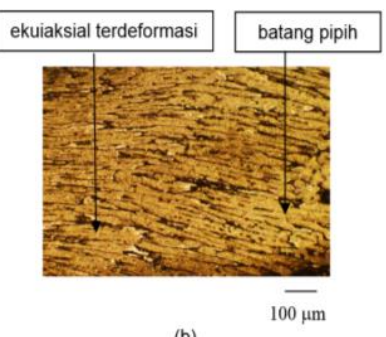

(b)
Gambar 5. Mikrograf
Zr- $\quad 0,3 \% \mathrm{Nb}-\quad 0,5 \% \mathrm{Fe}-0,5 \% \mathrm{Cr}$ pasca perlakuan panas $\left(650^{\circ} \mathrm{C}\right.$, 1,5 jam) dan pengerolan dingin.

(a) $r=5 \%$; (b) $r=10 \%$

Gambar 5 memperlihatkan pengaruh deformasi akibat pengerolan dingin terhadap mikrostruktur dari ingot paduan $\mathrm{Zr}-\quad 0,3 \% \mathrm{Nb}-\quad 0,5 \% \mathrm{Fe}-\quad 0,5 \% \mathrm{Cr}$ pasca perlakuan panas (650C; 1,5 jam). Pada reduksitebal $5 \%$,terjadi perubahan struktur butir dalam mikrostruktur paduan menjadi butir ekuiaksial terdeformasi dengan ukuran tidak seragam (Gambar 5a). Sementara itu, pada reduksi ketebalan $10 \%$, mikrostruktur paduan mempunyai struktur butir campuran yaitu butir ekuiaksial terdeformasi dan batang pipih (Gambar 5b). Perubahan bentuk butir tersebut disebabkan adanya tegangan tekan dari dua buah rol kerja yang mendapatkan perlawanan berupa gaya ikat antar atom dari paduan $\mathrm{Zr}-0,3 \% \mathrm{Nb}-0,5 \% \mathrm{Fe}-0,5 \% \mathrm{Cr}$. Apabila gaya ikat antar atom mampu menahan tekanan rol maka hanya terjadi perubahan bentuk butir dari ekuiaksial ke batang pipih. Semakin besar deformasi yang diterapkan pada paduan maka semakin besar pula tekanan yang harus diterima atom-atom dari paduan $\mathrm{Zr}-0,3 \% \mathrm{Nb}-0,5 \% \mathrm{Fe}-0,5 \% \mathrm{Cr}$. Kondisi tersebut ditambah dengan adanya dua struktur butir yang berbeda dalam paduan mengakibatkan terjadinya efek pengerasan regangan (strain hardening) sehingga semakin besar deformasi yang diterapkan maka pengerasan regangan semakin tinggi dan paduan semakin keras dan getas. Hal ini mengakibatkan keadaan dari paduan $\mathrm{Zr}-\quad 0,3 \% \mathrm{Nb}-\quad 0,5 \% \mathrm{Fe}-\quad 0,5 \% \mathrm{Cr}$ pasca perlakuan panas $\left(650^{\circ} \mathrm{C} ; 1,5\right.$ jam) dan pengerolan dingin $(r=5-10 \%)$ tidak mampu menahan beban tekan rol sehingga sampel paduan retak ${ }^{[9]}$.

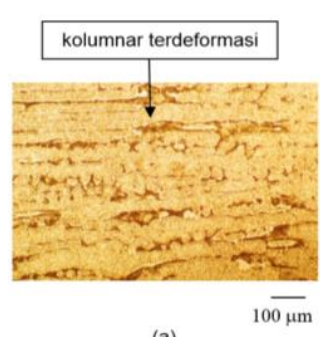

(a)

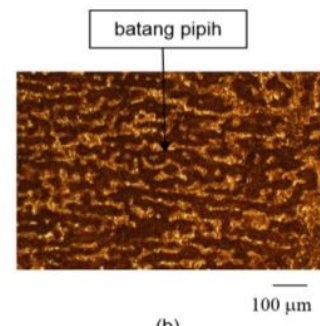

Gambar 6. Mikrograf ingot paduan $\mathrm{Zr}-\quad 0,3 \% \mathrm{Nb}-\quad 0,5 \% \mathrm{Fe}-0,5 \% \mathrm{Cr}$ pasca perlakuan panas $\left(650^{\circ} \mathrm{C}, 2\right.$ jam) dan pengerolan dingin.

(a) $r=5 \%$; (b) $r=10 \%$

Gambar 6 memperlihatkan pengaruh deformasi akibat pengerolan dingin terhadap mikrostruktur ingot paduan Zr- $\quad 0,3 \% \mathrm{Nb}-\quad 0,5 \% \mathrm{Fe}-\quad 0,5 \% \mathrm{Cr}$ pasca perlakuan panas $\left(650^{\circ} \mathrm{C}, 2\right.$ jam $)$. Pada reduksi 5\%, mikrostruktur paduan berupa butir kolumnar terdeformasi dengan ukuran butir relatif besar (Gambar 6a), kemudian berubah bentuk menjadi batang pipih pada reduksitebal 10\% (Gambar 6b). Perubahan bentuk dan ukuran butir dalam mikrostruktur paduan disebabkan oleh tegangan tekan dari dua buah rol kerja. Semakin besar deformasi yang diterapkan pada paduan maka semakin besar pula tegangan tekan yang harus diterima atom-atom dari paduan $\mathrm{Zr}-0,3 \% \mathrm{Nb}-0,5 \% \mathrm{Fe}-0,5 \% \mathrm{Cr}$. Oleh karena gaya ikat antar atom paduan pasca perlakuan panas dan pengerolan dingin mampu menahan tegangan tekan yang diterimanya maka paduan hanya berubah bentuk dan ukuran butirnya tanpa mengalami keretakan[10]. Dengan demikian paduan $\mathrm{Zr}-\quad 0,3 \% \mathrm{Nb}-0,5 \% \mathrm{Fe}-0,5 \% \mathrm{Cr}$ pasca perlakuan panas $\left(650^{\circ} \mathrm{C}, 2\right.$ jam $)$ mampu menerima deformasi dengan reduksi ketebalan 5-10\% tanpa mengalami keretakan.

Gambar 7 memperlihatkan mikrostruktur yang terjadi pada ingot paduan $\mathrm{Zr}-\quad 0,3 \% \mathrm{Nb}-\quad 0,5 \% \mathrm{Fe}-\quad 0,5 \% \mathrm{Cr}$ pasca perlakuan panas $\left(750^{\circ} \mathrm{C}, 1\right.$ jam $)$ yang telah mengalami pengerolan dingin dengan 
reduksi 5 dan 10\%.Mikrostruktur paduan berupa campuran butir ekuiaksial dan kolumnar yang terdeformasi padareduksi 5\% (Gambar 7a), sedangkan untuk reduksi 10\% mikrostrukturnya berupa batang pipih terdeformasi (Gambar 7b). Dengan demikian diketahui bahwa ingot paduan $\mathrm{Zr}-\quad 0,3 \% \mathrm{Nb}-\quad 0,5 \% \mathrm{Fe}-\quad 0,5 \% \mathrm{Cr}$ pasca perlakuan panas $\left(750^{\circ} \mathrm{C}, 1\right.$ jam $)$ tidak memenuhi syarat untuk menerima perlakuan mekanik berupa pengerolan dingin dengan reduksi ketebalan $5-10 \%$.

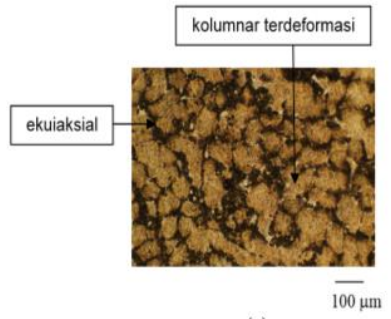

(a)

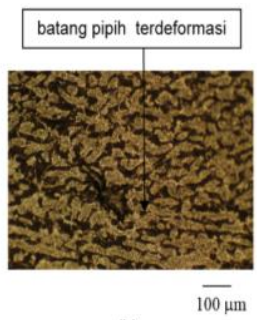

Gambar 7. Mikrograf ingot paduan Zr- $\quad 0,3 \% \mathrm{Nb}-\quad 0,5 \% \mathrm{Fe}-0,5 \% \mathrm{Cr}$ pasca perlakuan panas $\left(750^{\circ} \mathrm{C}, 1\right.$ jam) dan pengerolan dingin.

(a) $r=5 \%$; (b) $r=10 \%$

$\begin{array}{crr}\text { Gambar } & 8 & \text { memperlihatkan } \\ \text { mikrostruktur pada ingot paduan }\end{array}$ $\mathrm{Zr}-\quad 0,3 \% \mathrm{Nb}-\quad 0,5 \% \mathrm{Fe}-\quad 0,5 \% \mathrm{Cr}$ pasca perlakuan panas $\left(750^{\circ} \mathrm{C} ; 1,5\right.$ jam $)$ dan pengerolan dingin dengan reduksi ketebalan 5 dan $10 \%$. Pada reduksi 5\%, mikrostruktur paduan berupa butir ekuiaksial terdeformasi (Gambar 8a) sedangkan reduksi 10\% berupa batang pipih terdeformasi (Gambar 8b).

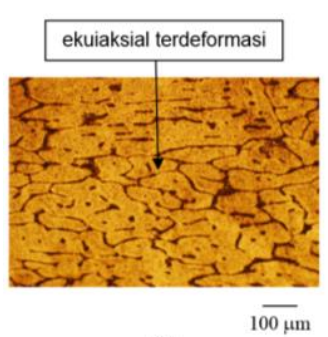

(a)

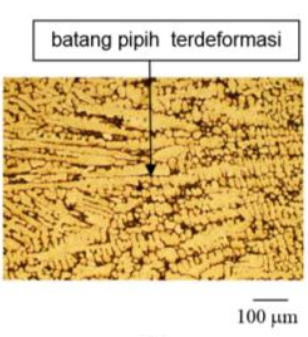

(b)
Gambar 8. Mikrograf ingot paduan Zr- $\quad 0,3 \% \mathrm{Nb}-\quad 0,5 \% \mathrm{Fe}-0,5 \% \mathrm{Cr}$ pascaperlakuan panas $\left(750^{\circ} \mathrm{C}\right.$, 1,5 jam) dan pengerolan dingin. (a) $r=5 \%$; (b) $r=10 \%$

Gambar 9 memperlihatkan mikrostruktur yang terdapat pada ingot paduan $\mathrm{Zr}-0,3 \% \mathrm{Nb}-0,5 \% \mathrm{Fe}-0,5 \% \mathrm{Cr}$ pasca perlakuan panas $\left(750^{\circ} \mathrm{C}, 2\right.$ jam) dan pengerolan dingin dengan reduksi tebal 5 dan $10 \%$. Mikrostruktur paduan pasca reduksi $5 \%$ berupa butir ekuiaksial terdeformasi (Gambar 9 a), pasca reduksi $10 \%$ berupa batang pipih terdeformasi (Gambar 9 b).

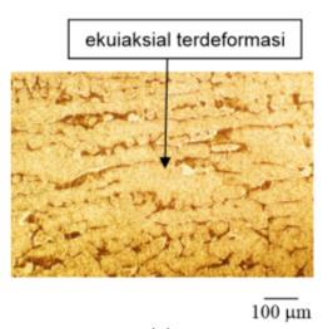

(a)

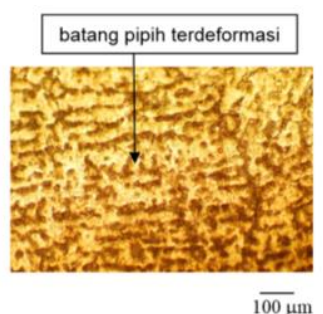

(b)
Gambar 9. Mikrograf ingot paduan Zr- $\quad 0,3 \% \mathrm{Nb}-\quad 0,5 \% \mathrm{Fe}-0,5 \% \mathrm{Cr}$ pasca perlakuan panas $\left(750^{\circ} \mathrm{C}, 2\right.$ jam) dan pengerolan dingin.

(a) $r=5 \%$; (b) $r=10 \%$

Adanya perubahan bentuk butir dalam ingot paduan $\mathrm{Zr}-0,3 \% \mathrm{Nb}-0,5 \% \mathrm{Fe}$ $0,5 \% \mathrm{Cr}$ yang terjadi pasca pengerolan dingin (Gambar 8 dan 9) disebabkan oleh tekanan dua buah rol kerja terhadap paduan yang relatif lunak. Hal ini ditandai bentuk ekuiaksial terdeformasi pasca pengerolan dingin dengan reduksi tebal 5\%. Selanjutnya berbentuk batang pipih (Gambar 8b) dan batang pipih terdeformasi (Gambar 9b) pasca pengerolan dingin dengan reduksi $10 \%$. Kondisi tersebut menyebabkan ingot paduan $\mathrm{Zr}-0,3 \% \mathrm{Nb}-0,5 \% \mathrm{Fe}-0,5 \% \mathrm{Cr}$ pasca perlakuan panas $750^{\circ} \mathrm{C}$ dengan waktu penahanan 1,5 dan 2 jam mampu menerima deformasi 5- 10\% tanpa mengalami keretakan.

Deformasi dingin yang diterapkan pada paduan mengakibatkan terjadinya interaksi antara satu dislokasi dengan dislokasi lainnya, dan selanjutnya dislokasi tersebut bergerak dalam bidang luncurnya menuju permukaan paduan. Selama perjalanannya, gerakan dislokasi dihambat oleh suatu penghalang berupa atom asing atau presipitat dalam kisi kristal. Hal ini akan mengakibatkan terjadinya penumpukan dislokasi di penghalang sehingga 
menghasilkan tegangan balik yang melawan tegangan pada bidang slip. Selain itu juga terjadi dislokasi yang bergerak memotong di bidang slip aktif. Hal ini akan menghasilkan simpangan yang membatasi gerak dislokasi sehingga memperbesar pengerasan regang (strain hardening) ${ }^{[11]}$. Semakin besar deformasi plastis yang diterapkan maka efek pengerasan regangan semakin besar pula sehingga mengakibatkan ingot paduan Zr- 0,3\% Nb- 0,5\%Fe- $0,5 \% \mathrm{Cr}$ semakin keras dan getas.

Berdasarkan Gambar 4 sampai dengan Gambar 9 diketahui bahwa perlakuan panas dan deformasi dingin dapat mengubah bentuk mikrostruktur paduan Zr- $\quad 0,3 \% \mathrm{Nb}-0,5 \% \mathrm{Fe}-0,5 \% \mathrm{Cr}$ dari butir ekuiaksial ke bentuk pipih terdeformasi sehingga mampu meningkatkan kekuatan paduan tanpa mengalami keretakan.

\section{b. Karakterisasi fasa}

Paduan $\mathrm{Zr}-0,3 \% \mathrm{Nb}-0,5 \% \mathrm{Fe}-0,5 \% \mathrm{Cr}$ pasca perlakuan panas $\left(750^{\circ} \mathrm{C}, 2\right.$ jam $)$ dan pengerolan dingin $(r=10 \%)$ dikarakterisasi menggunakan XRD untuk mengetahui struktur kristal dan fasa-fasa yang ada dalam paduan. Gambar 10 menunjukkan spektrum logam, unsur pemadu dan senyawa-senyawa yang terbentuk.

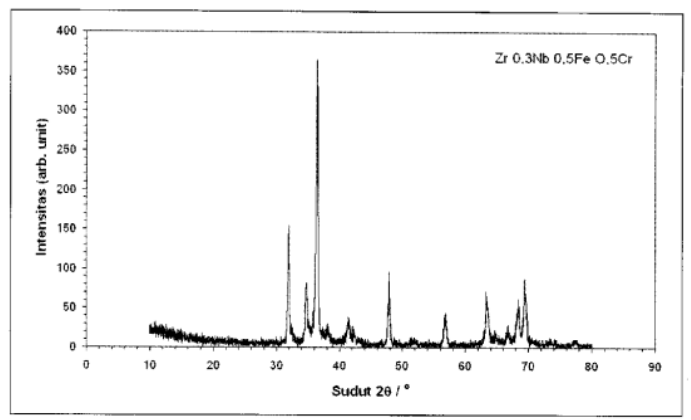

Gambar 10. Difraktogram sinar-X paduan $\mathrm{Zr}$ - $\quad 0,3 \% \mathrm{Nb}-0,5 \% \mathrm{Fe}-0,5 \% \mathrm{Cr}$ pasca perlakuan panas $\left(750^{\circ} \mathrm{C}\right.$, 2 jam) dan pengerolan dingin $(r=10 \%)$

Sementara itu, identifikasi puncak spektrum difraksi sinar $\mathrm{X}$ dari ingot paduan Zr- $0,3 \% \mathrm{Nb}-0,5 \% \mathrm{Fe}-0,5 \% \mathrm{Cr}$ diperlihatkan pada Tabel 1, sedangkan Tabel 2 menunjukkan identifikasi fasa-fasa yang terdapat di dalam ingot paduan $\mathrm{Zr}-\quad 0,3 \% \mathrm{Nb}-\quad 0,5 \% \mathrm{Fe}-\quad 0,5 \% \mathrm{Cr}$ pasca perlakuan panas dan pengerolan dingin.

Tabel 1. Identifikasi puncak spektrum paduan $\mathrm{Zr}-0,3 \% \mathrm{Nb}-0,5 \% \mathrm{Fe}-0,5 \% \mathrm{Cr}$ pasca perlakuan panas $\left(750^{\circ} \mathrm{C}, 2 \mathrm{jam}\right)$ dan pengerolan dingin $(r=10 \%)$.

\begin{tabular}{|c|c|c|c|c|c|c|c|}
\hline No: & 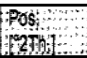 & WhH & Area & Baptofitas: & dispacing & afleight & RELithat: \\
\hline 1 & 31.9187 & 0.1968 & 27.7 & 3 & 2.80386 & 142.7 & 51.07 \\
\hline 2 & 34.8395 & 0.3542 & 23.44 & 3 & 2.5752 & 67.07 & 24 \\
\hline 3 & 36.5442 & 0.0984 & 27.12 & 3 & 2,45889 & 279.42 & 100 \\
\hline 4 & 38.1781 & 0.3149 & 6.62 & 3 & 2.35734 & 21.32 & 7.63 \\
\hline 5 & 41.4346 & 0.3936 & 10.8 & 2 & 2.17928 & 27.81 & 9.95 \\
\hline 6 & 42.4031 & 0.3149 & 3.96 & 2 & 2.13172 & 12.76 & 4.57 \\
\hline 7 & 47.8661 & 0.3542 & 25.25 & 1 & 1.90041 & 72.27 & 25.86 \\
\hline 8 & 52.0763 & 0.9446 & 3.91 & 2 & 1.75624 & 4.2 & 1.5 \\
\hline 9 & 56.8399 & 0.4723 & 15.76 & 3 & 1.61985 & 33.83 & 12.11 \\
\hline 10 & 63.3411 & 0.3542 & 20.2 & 3 & 1.46836 & 57.82 & 20.69 \\
\hline 11 & 64.7819 & 0.4723 & 5.4 & 3 & 1.43914 & 11.58 & 4.15 \\
\hline 12 & 66.8164 & 0.4723 & 7.65 & 3 & 1.40018 & 16.42 & 5.88 \\
\hline 13 & 68.4657 & 0.551 & 23 & 3 & 1.37041 & 42.31 & 15.14 \\
\hline 14 & 69.3977 & 0.1574 & 12.17 & 3 & 1.35427 & 78.35 & 28.04 \\
\hline 15 & 77.5866 & 0.672 & 4 & 3 & 1.2295 & 4.46 & 1.6 \\
\hline
\end{tabular}

Tabel 2. Identifikasi fasa dalam paduan $\mathrm{Zr}-0,3 \% \mathrm{Nb}-0,5 \% \mathrm{Fe}-0,5 \% \mathrm{Cr}$ pasca perlakuan panas $\left(750^{\circ} \mathrm{C}, 2\right.$ jam $)$ dan pengerolan dingin $(r=10 \%)$.

\begin{tabular}{|c|c|c|c|}
\hline 2 theta & d-spacing $(\AA)$ & Intensitas & Match \\
\hline 31,97 & 2,799481 & 27,7 & $\mathrm{Zr}, \mathrm{Zr}_{2} \mathrm{Fe}$ \\
\hline 34,84 & 2,575200 & 23,4 & $\mathrm{Zr}, \mathrm{Zr}_{2} \mathrm{Fe}$ \\
\hline 36,54 & 2,458893 & 27,1 & $\mathrm{Zr}$ \\
\hline 38,18 & 2,357337 & 6,6 & $\mathrm{Zr}_{2} \mathrm{Fe}$ \\
\hline 41,43 & 2,179282 & 10,8 & $\mathrm{ZrCr}_{2}$ \\
\hline 4,4 & 2,131723 & 4,0 & $\begin{array}{l}\mathrm{FeCr}, \\
\mathrm{ZrCr}_{2}\end{array}$ \\
\hline 47,87 & 1,900409 & 25,2 & $\mathrm{Zr}$ \\
\hline 52,08 & 1,756243 & 3,9 & $\mathrm{FeCr}$ \\
\hline 63,34 & 1,468356 & 20,2 & $\mathrm{ZrCr}_{2}$ \\
\hline 64,78 & 1,439138 & 5,4 & $\mathrm{Zr}_{2} \mathrm{Fe}$ \\
\hline 66,82 & 1,400176 & 7,7 & $\mathrm{Zr}, \mathrm{Zr}_{2} \mathrm{Fe}$ \\
\hline 68,47 & 1,370415 & 23,0 & $\mathrm{Zr}$ \\
\hline 69,4 & 1,354272 & 12,2 & $\mathrm{Zr}$ \\
\hline 77,59 & 1,230521 & 4,0 & $\mathrm{Zr}$ \\
\hline
\end{tabular}

Berdasarkan Tabel 1 dan Tabel 2 diketahui fasa-fasa yang terdapat dalam ingot paduan $\mathrm{Zr}-0,3 \% \mathrm{Nb}-0,5 \% \mathrm{Fe}-0,5 \% \mathrm{Cr}$ pascaperlakuan panas dan pengerolan dingin adalah $\mathrm{Zr}$, $\mathrm{Fe} \mathrm{Cr}$, $\mathrm{Zr}_{2} \mathrm{Fe}$ dan $\mathrm{ZrCr}_{2}$. Zirkonium dari basis data PDF2 dengan kartu 00-005-0665 mempunyai struktur kristal heksagonal dengan parameter kisi $a=3,232$ $\AA$, $b=3,232 \AA$ dan $\mathrm{c}=5,147 \AA$. Struktur kristal $\mathrm{Fe} \mathrm{Cr}$ dari basis data PDF2 dengan kartu 00- 005-0708 adalah tetragonal dengan 
parameter kisi $a=8,7995 \AA$, dan $c=4,5442 \AA$. Struktur kristal $\mathrm{Zr}_{2} \mathrm{Fe}$ dari basis data PDF2 dengan kartu 00-019-0645 adalah tetragonal dengan parameter kisi $a=6,457 \AA$ dan $\mathrm{C}=5,542 \AA$ A. Struktur kristal $\mathrm{ZrCr}_{2}$ dari basis data PDF2 dengan kartu00-006-0613 adalah heksagonal dengan parameter kisi $a=5,089$ $\AA$, $b=5,089 \AA$ dan $c=8,279 \AA$. Unsur pemadu utama yaitu $\mathrm{Nb}$ larut padat dalam $\beta-\mathrm{Zr}$.

Adanya senyawa $\mathrm{Zr}_{2} \mathrm{Fe}$ dan $\mathrm{ZrCr}_{2}$ dapat meningkatkan kekuatan mekanik paduan $\mathrm{Zr}-0,3 \% \mathrm{Nb}-0,5 \% \mathrm{Fe}-0,5 \% \mathrm{Cr}$. Selain itu, senyawa $\mathrm{FeCr}$ dapat meningkatkan ketahanan korosi pada ingot paduan $\mathrm{Zr}-\quad 0,3 \% \mathrm{Nb}-\quad 0,5 \% \mathrm{Fe}-0,5 \% \mathrm{Cr}$. Dengan demikian membuktikan bahwa penambahan $\mathrm{Fe}$ dan $\mathrm{Cr}$ sebagai unsur pemadu dapat meningkatkan kekuatan mekanik dan ketahanan korosi paduan $\mathrm{Zr}-\mathrm{Nb}^{[2,10]}$

\section{SIMPULAN}

Pemeriksaan mikrostruktur paduan
$\mathrm{Zr}-\quad 0,3 \% \mathrm{Nb}-\quad 0,5 \% \mathrm{Fe}-0,5 \% \mathrm{Cr}$ pasca perlakuan panas $\left(650^{\circ} \mathrm{C}, \quad 1-2\right.$ jam $)$ mempunyai struktur butir ekuiaksial dengan ukuran butir bertambah besar seiring dengan bertambahnya durasi waktu pemanasan. Mikrostruktur yang terjadi pada paduan $\mathrm{Zr}-\quad 0,3 \% \mathrm{Nb}-\quad 0,5 \% \mathrm{Fe}-\quad 0,5 \% \mathrm{Cr}$ pasca perlakuan panas $750^{\circ} \mathrm{C}$ mempunyai struktur butir ekuiaksial dan kolumnar ( $\mathrm{t}=1 \mathrm{jam})$, butir kolumnar dan butir ekuiaksial relatif besar ( $\mathrm{t}=1,5 \mathrm{jam})$ dan mengarah ke butir ekuiaksial relatif besar $(t=2$ jam $)$.

Paduan $\mathrm{Zr}-0,3 \% \mathrm{Nb}-0,5 \% \mathrm{Fe}-0,5 \%$ $\mathrm{Cr}$ pasca perlakuan panas $\left(650^{\circ} \mathrm{C}, 1 \mathrm{jam}\right)$ dan $\left(750^{\circ} \mathrm{C}, 1 \mathrm{jam}\right)$ tidak dapat dirol dingin dengan reduksi ketebalan5 - 10\%. Paduan $\mathrm{Zr}-0,3 \% \mathrm{Nb}-0,5 \% \mathrm{Fe}-0,5 \% \mathrm{Cr}$ pasca perlakuan panas $\left(650^{\circ} \mathrm{C}, 2 \mathrm{jam}\right)$ dan $\left(750^{\circ} \mathrm{C}, 1,5-2 \mathrm{jam}\right)$ mampu menerima deformasi dingin dengan reduksi ketebalan $5-10 \%$ tanpa mengalami keretakan.

Senyawa Zr2Fe, ZrCr2dan $\mathrm{FeCr}$ teridentifikasi dari hasil uji kristalografi pada paduan $\mathrm{Zr}-0,3 \% \mathrm{Nb}-0,5 \% \mathrm{Fe}-0,5 \% \mathrm{Cr}$.

\section{UCAPAN TERIMA KASIH}

Penulis mengucapkan terima kasih kepada Isfandi, A.Md dan Yatno Dwi Agus Santosa (PTBBN) yang telah membantu dalam pembuatan ingot dan pengamatan mikrostruktur paduan $\mathrm{Zr}-\mathrm{Nb}-\mathrm{Fe}-\mathrm{Cr}$.

\section{DAFTAR PUSTAKA}

[1] Rudling, P., R. Adamson, B. Cox, F. Garzarolli and A. Strasser, (2008), High Burnup Fuel Issues, Nuclear Engineering and Technology, Vol..40, 1, Hal. 1-8.

[2] Wang, J., H. Fan, J. Xiong, H. Liu, Z. Miao, S. Ying and G. Yang, (2011). Effects of $\mathrm{Fe}$ and $\mathrm{Cr}$ on Corrosion Behaviour of $\mathrm{ZrFeCr}$ Alloys in $500^{\circ} \mathrm{C}$ Steam, J. Nuclear and Engineering Design, 241, Hal. 471-475.

[3] Lim, Y.S. H.G. Kim and Y.H. Jeong, (2008). Recrystallization Behavior of Zr$x \mathrm{Nb}$ Alloys, Materials Transaction, 49 (7), Hal. 1702-1705.

[4] Kim, T.K., P.S. Choi, S.K. Yang, C.T. Lee and D.S. Shon, (2008). Correlation Between The Tensile Strength and Corrosion Behavior of Heat Treated Zr$1.0 \mathrm{Nb}$ Alloy, Nuclear Engineering and Technology, 40 (6), Hal. 505-510.

[5] Zhinan, Y., L. Fengchao, Y. Zhigang, Z. Fucheng, (2013), Effect of Annealing on Microstructure and Hardness of Hot and Cold Rolled Zr705, Rare Metal Materials and Engineering Volume 42, 2, Hal. 254 $-258$.

[6] Oh, S., C.i Jang, J. H. Kim, Y. H. Jeong, (2010), Effect of $\mathrm{Nb}$ on Hydride Embrittlement of Zr-xNb Alloys, J. Material Science and Engineering, Vol. 527, Hal. 1306-1313.

[7] Straumal, B. B., A. S. Gornakova, Y. O. Kucheev, B. Baretzky and A. N. Nekrazov, (2012), Grain Boundary Wetting by a Second Solid Phase in the Zr-Nb Alloys, JMEPEG, 21, Hal. 721724. 
[8] Kalpakjian, S, (2006), Manufacturing Engineering and Technology, Addition Wesley Publ. Co, Massachussets, USA.

[9] Choi, M. Y., C. Y. Lee, Y. Kim, Y. K. Mok, S. J. Lee, J..M. Suh, (2013), Effects of Final Annealing on the Corrosion Behavior and Hardness of Zr-Nb-Fe-P Alloy, Transactions of the Korean Nuclear Society.
[10] Kim, H. G., S. Y. Park, M. H. Lee, Y. H. Jeong, S. D. Kim, (2008), Corrosion and Microstructural Characteristics of $\mathrm{Zr}-\mathrm{Nb}$ Alloys with Different Nb Contents, J. of Nuclear Materials 373, Hal. 429-432.

[11] Min Ma, M. Li, Y. Tan, H. Yuan and W. Liu, (2014). Microstructure and Texture Evolution in Commercial-Purity Zr 702 During Cold Rolling and Annealing, J. of Minerals, Metalurgy and Materials, 21 (8), Hal. 75-79. 
Vol. 21 No. 2, Juni 2015 : 47 - 94 